\section{Mu süda, ärka üles}

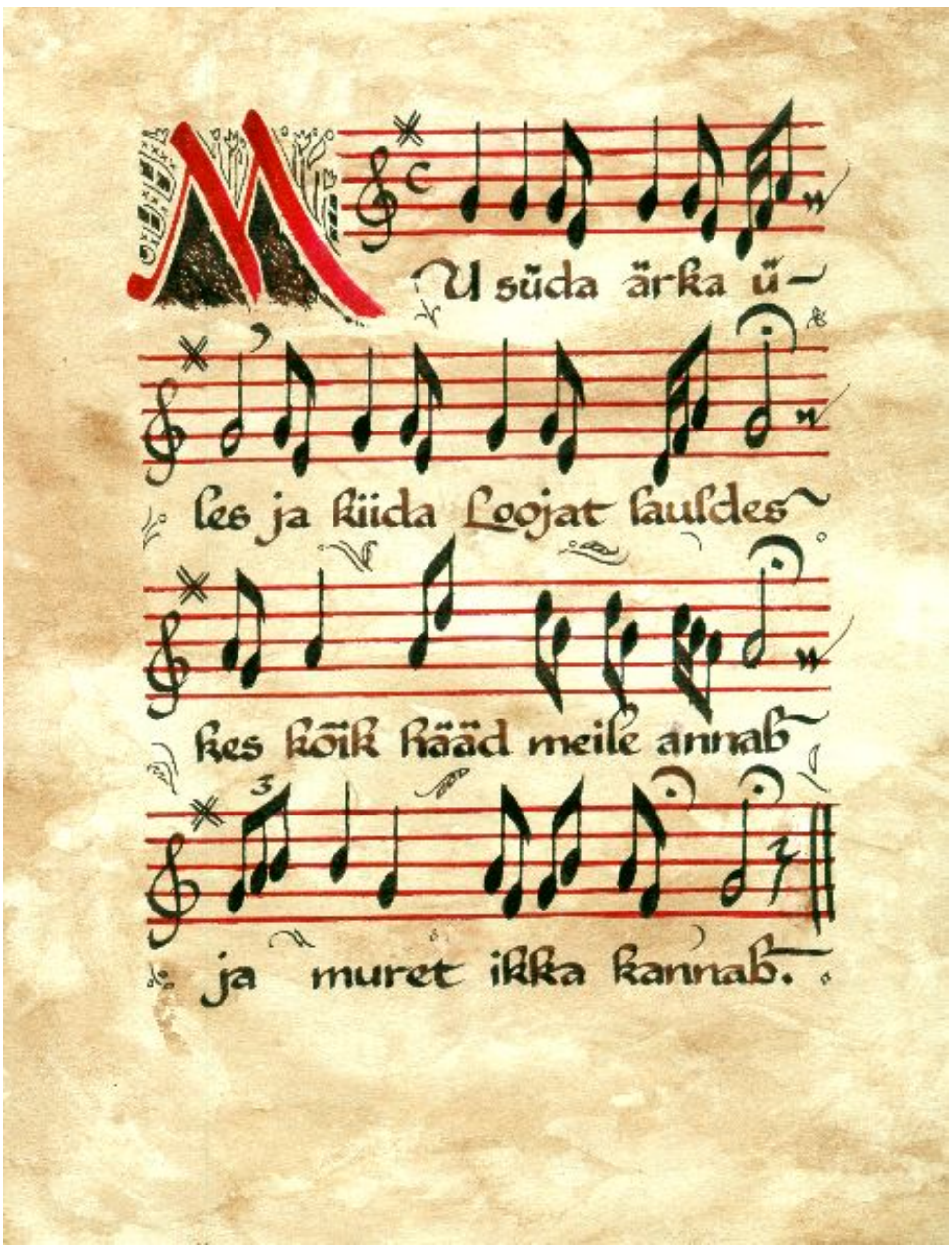

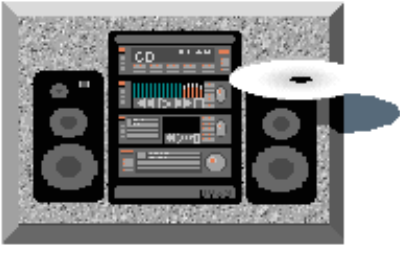

7.6 Mb .mp3

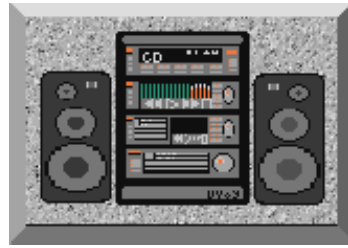

$2.4 \mathrm{Mb} . \mathrm{mp} 3$
Vaimulik rahvalaul Hiiumaalt

Ansambel Triskele

Noodi joonistas Eve Valper

Kommentaar: Ergo-Hart Västrik

Mu süda, ärka üles

Ja kiida Loojat lauldes,

Kes kõik head meile annab

Ja muret ikka kannab.

Kui magama ma heitsin,

End Isa sülle peitsin,

Mind saadan püüdis neelda,

Kuid Jumal võttis keelda.

Tõest, Isa, kui ta vahtis,

Mind kätte saada tahtis,

Siis sa mind sülle võtsid

Ja oma käega katsid.

«Jää rahul',» hüüdsid sina,

«Mu laps, sind kaitsen mina!

Ta ei saa kahju teha,

Sa saad veel päeva näha.»

Su sõna tõeks läinud,

Ma olen päeva näinud,

Ei häda saand mu ligi,

Mind varjas sinu vägi.

See eest ma sind nü̈̈d tänan, suurt auu sulle annan,

Sull' ohvrin õhkamisi

Ja pühi palumisi.

Sa näed mu südamesse Ja tead, mu Jumal, ise, Et paremat ei ole

Mul anniks tuua sulle.

Mu Jumal, nii kui ööse

Mind hoidis sinu käsi,

Nii päeva ka mind kanna,

Mull' inglid varjuks anna.

Ka töös mind ise aita,

Mis õige, mulle näita!

Su hoolde kõik ma jätan,

Mis iial ette võtan.

Su heldus jäägu mulle, Mu süda templiks sulle:

Su sõna mind siin toitku,

Teed taeva poole näitku. 


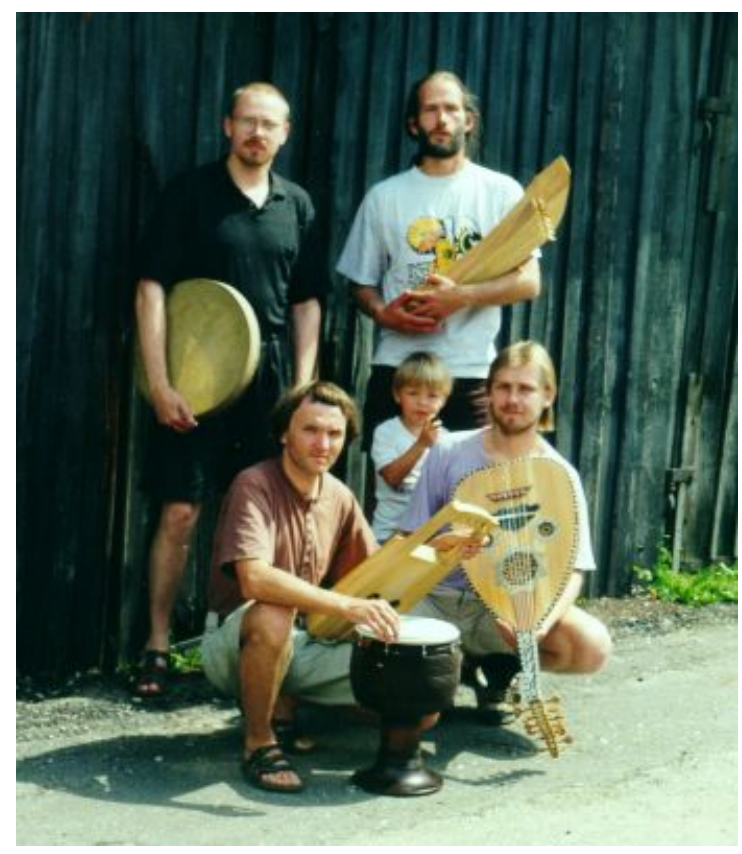

\section{Triskele}

Tarmo Tabas - laul

Heikki-Rein Veromann - flööt, laul

Jaanus Roosileht - fiidel, laul

Toivo Sõmer - kannel, laul

Janno Mäe - trumm, laul

Lindistus - Urmas Taniloo,

Tartu Ülikooli aula, november 1999

Triskele praeguse koosseisu liikmed on kõik vähemal või rohkemal määral kokku puutunud Euroopa keskaja muusika esitamisega ansamblis Via Sonora. Samuti ühendab neid sügav huvi eri maade rahvamuusika vastu - muusikuid võlub araabia (ja üldse ida) muusikapärandile omane lähenemine, kus suhe interpreedi ja muusika vahel on intensiivne ning ennastunustav. Triskele muusika vormi ja stiili variatiivsus - selle kohatine ebaselgus, hämarus ja adumatus - väljendub ilmekalt muusikute improvisatsioonide lihvimata ja lahtistes otstes, kajastades nõnda «ebatäiusliku inimese püüdu otsida ja tajuda omal moel jumaliku loomisakti saladuslikke tagamaid». Triskele pole seadnud eesmärgiks algmaterjali autentselt esitada, vaid luua konkreetsest tekstist ja viisist lähtuvaid nägemuspilte, mis püüdlevad ajast ja ilmakorrast sõltumatu vaimsuse kandjateks. Triskele peamisteks inspiratsiooniallikateks on olnud eesti regilaulupärand ning rahvapärased koraaliviisid. Alates 1997. aastast on Triskele andnud kontserte Viljandi pärimusmuusika festivalil ning kirikutes Eesti eri paigus. 


\section{Kommentaar}

Vaimulikud rahvaviisid kui seni suurel määral avastamata muusikaline allikmaterjal on viimase 10-15 aasta jooksul köitnud paljude rahvamuusika esitajate ja töötlejate tähelepanu. Omal moel võib kõneleda koguni vaimulike rahvalaulude buumist, kui võtta arvesse nt Eesti Rahvaluule Arhiivis käinute huvi just selle viisikogumi vastu. Kuulajateni on jõudnud 1990. aastatel ridamisi uusi esitusi ja tõlgendusi, $\stackrel{\perp}{ }$ kuigi - mis siin salata - praegugi napib nii esitajatel kui ka kuulajatel asja kohta lähemat teavet.

Piiripealse oleku tõttu, asetsedes kirjaliku ja suulise traditsiooni vahealas, ning tõenäoliselt ka ideoloogilistel põhjustel, pole rahvapärased koraaliviisid leidnud teed esinduslikesse eesti rahvamuusika antoloogiatesse. Ja kuigi algust on tehtud vaimulike rahvalaulude teadusliku uurimisega, pole Eestis põhjapanevaid uurimusi ega viisikogumikke siiani muusikahuvilise ette jõudnud. Tõenäoliselt just seetõttu on vaimulike rahvalaulude ümber tekkinud teatud salapära oreool. 20. sajandi alguses kogutud viisid on andnud alust mitmeteks spekulatsioonideks: sealt on saadud innustust Eesti keskaja muusika ja algupärase vaimuliku repertuaari otsimisel, teisalt on rahvapäraseid koraaliviise peetud üheselt rootsilaenulisteks või siis vaid usuäratusliikumiste tegevuse viljaks. Et paljud küsimused vaimulike rahvalaulude kohta on veel vastuseta, siis on siinne kommentaargi enam arutlevat laadi, taustteavet vahendav ning püüab kokku viia erinevaid seiku Triskele esitusele aluseks olnud viisi- ja tekstiteisendit silmas pidades.

Maakeelset koguduselaulu tunti Eestis kindlasti juba 16. sajandi keskpaigas, mil siinsete pastorite kasutada olid käsikirjalised laulutõlgete kogumikud (ühest sellisest, Hans Susi 1551. a tõlkest, lähemalt vt Masing 1964). Esimene eestikeelne lauluraamat ilmus 1637. aastal Tallinnas Heinrich Stahli «Käsi- ja koduraamatu» teise osana ning sisaldas 144 tolleaegse luteri kiriku üldisesse lauluvarasse kuuluvat laulu koos saksakeelsete alustekstidega. Kui Stahli käsiraamatu laulud olid rea-alused proosatõlked, mida laulda oli küllalt tülikas, siis järgmised lauluraamatu trükid alates 1656. aastast pakkusid juba riimitud laulutekste. Lisaks 18. sajandi alguses laiatarbekaubaks muutunud lauluraamatutele aitasid koguduselaulu levikule kaasa Rootsi aja lõpul loodud kihelkonna- ja külakoolid ning järkjärguline kirjaoskuse kasv, alates 1730. aastatest aga ka pietistlikud usuliikumised, mis ühislaulmist laialt propageerisid (Lepnurm 1999: 166; Põldmäe 1987: 180; Põldmäe 1988).

Kirikukoraal «Mu süda, ärka üles» põhineb Paul Gerhardti (1607-1676) värsstekstil «Wach auf, mein Herz, und singe». Eesti keelde tõlkis laulu 17. sajandi lõpus tõenäoliselt Otepää kirikuõpetaja Adrian Virginius ning esmakordselt avaldati see teadaolevalt 1690. aastal lõunaeestikeelses lauluraamatus «Tarto-Ma Kele Laulu-Ramat» (lk 209-210). Neli aastat hiljem ilmus laul Johann Hornungi poolt kohendatuna juba ka põhjaeesti keeles Riias välja antud kirikumanuaali «Ma Kele Koddo ning Kirgo Ramat» laulukogumikus «Ma=Kele Uus Laulo=Ramat» (lk 175). Väga laialt see Põhjasõja-eelse aja silmapaistvaim põhjaeestikeelne teos rahva hulgas siiski levida ei jõudnud - raamatu eessõnas olnud kriitiliste avalduste tõttu teenis teos Eestimaa vaimulike pahameele ning see keelustati kuningas Karl XI käsul (Masing, Soosaar 1956: 49). 
Üldise tuntuse saavutas laul kindlasti juba 18. sajandi teisel veerandil - mõneti täiendatud ja parandatud kujul avaldati tõlge alates 1721. aastast põhjaeesti murdealal üldkasutatavaks saanud «Eesti=Ma Kele Laulo=Ramatus», mida trükiti (küll väikeste lisandustega) järgneva pooleteise sajandi jooksul üle 100000 eksemplari (EKA I: 185). On ilmne, et just selle, nn vana lauluraamatu vahendusel said luteri koraalid Põhja-Eestis maarahvale üldiselt omaseks ja välja kujunes rahvalik koraalilaulmise traditsioon. Lauluraamatu uue redaktsiooni väljaandmiseni jõuti alles 1899. aastal. Sellest, nn Uuest Lauluraamatust, on võetud ka Triskele esitatud laulu sõnad (nr 65).

Tõenäoliselt ei erinenud laulu «Mu süda, ärka üles» viis 17.-18. sajandi algallikates² olulisel määral viisist J. L. E. Punscheli kogumikus, mis sai alates 1839. aastast normatiivseks luterlikuks koraaliraamatuks kogu Eesti alal. Ometi kaebasid kaasaegsed (Punschel nende hulgas), et kogudustes lauldi koraale «moonutatult», «vääritute ja maitsetute kaunistustega» ning et neid sobitati kokku mitmetest viisidest (Salumäe 1988: 47). Pole midagi imekspandavat, et eeslaulmisel põhinev laulutraditsioon (koguduselaulu saatmine orelil sai maakirikutes üldiseks alles 19. sajandil) aja jooksul pooleldi märkamatult varieerus ning eri paigus kujunesid aegade jooksul välja kindlapiirilisemad lokaalsed variandid ning laulmistraditsioonid (Lippus 1988: 29). Kirikulaul folkloriseerus - tekkisid vaimulikud rahvalaulud, mille viisid erinesid kanoniseeritud algkujudest juba tunduvalt, kajastades tõenäoliselt ka märksa varasemat muusikalist mõtlemist, ornamenteerimis- ja esitamismaneeri, kui see oli iseloomulik reformeeritud kiriku poolt viljeldud koraalilaulule.

Rahvapäraseid koraaliviise hakati Eestis teadlikult üles kirjutama aastatel 1904-1921 Eesti Üliõpilaste Seltsi poolt korraldatud rahvaviiside kogumise aktsiooni raames (lähemalt vt Leichter 1932; Tampere 1971). Rahvaviise käisid O. Kallase juhendamisel kogumas mitmed toonased Peterburi konservatooriumi üliõpilased, sh mitmed hilisemad tuntud eesti heliloojad, nagu P. Süda, M. Saar, J. Aavik, M. Hermann (Härma), C. Kreek jt. On mõneti paradoksaalne, et kogujate huvivälja vaimulikud laulud üleüldse sattusid, sest 1904. aastal Postimehes avaldatud EÜS-i kogumisüleskutses «Eesti muusikasõpradele» oli rõhutatud just kirikulaulu negatiivset osa vanade rahvaviiside kadumisel (ERtA II: 17-19; Tedre 1998: 160-162). Vaimulikke rahvaviise on siiski põgusalt nimetatud kogujatele kaasa antud juhistes: «Kas eestlastel ei ole ka rahvaloodud (ehk moonutatud) vaimulikka viisisid (nt koraalid «ööritamistega» Saaremaal)? Soomlastelt on hulk niisuguseid saadud.» (EFAM, EÜS M6; vt ka Järg 1987: 116). Tähelepanu sellele viisikogumile juhtiski soome muusikateadlane Ilmari Krohn, kelle näpunäidete kohaselt kogumisjuhised koostati ning kes oli ise selleks ajaks soome vaimulikke rahvaviise uurinud.

Kokku saadi EÜS-i kogumisaktsiooni käigus 291 vaimulikku viisi (Leichter 1932: 177). Rahvapärased koraaliviisid olid tuntud üle kogu maa, kuid enim koguti neid Lääne-Eestis (vt samas). Rahvapäraste koraaliteisendite suurimaks kogujaks Eestis võib õigusega nimetada Cyrillus Kreeki, kelle välitööd ulatuvad ka Noarootsi ja Vormsi eestirootslaste juurde. $\underline{3}$ Hilisematel kogumiskäikudel keskendubki C. Kreek peaasjalikult vaimulike rahvalaulude jäädvustamisele, tehes salvestusi ka fonograafiga. Vaimulikud rahvalaulud, nii tema enda kogutud kui ka teiste kogudest kopeeritud, on olulisel kohal ka Kreegi loomingus - neil põhinevaid kolme- ja neljahälseid kooriseadeid on Kreegil üle 440, lisaks poolteistsada vaimulikel rahvaviisidel põhinevat kaanonit orelile (vt Humal 1989). 
Ka laulu «Mu süda, ärka üles» kõik viisiteisendid on pärit Lääne-Eestist. Laul on kuulunud kindlasti populaarseimate kirikukoraalide hulka, mida kinnitavad Eesti Rahvaluule Arhiivis ning Teatri- ja Muusikamuuseumis leiduvad 7 teisendit (tõsi küll, 5 neist eestirootslastelt). Kõige varem kirja pandud viisi (arhiiviviide EÜS II 796 (40)), mis on aluseks ka praegusele Triskele esitusele, laulis 1905. aastal Peeter Südale tema esimesel kogumiskäigul Hiiumaale 56-aastane Peeter Jalaja, kes elas Reigi kihelkonnas Mägipe külas. Kokku kogus P. Süda sellel Hiiumaa kogumiskäigul 11 vaimulikku rahvaviisi, mis moodustas tema poolt üleskirjutatud viiside üldarvust siiski vaid väikese osa. Enamik kirjapandud lauludest olid riimilised rahvalaulud, sekka mõni lastelauluna püsinud regilaul.

Teine viisiteisend (EÜS XI 1002 (26)), mis kogutud 1914. aastal Nissi kihelkonnas, on põlistatud ainukese vaimuliku rahvalauluna praegu kasutatavas luteri koraaliraamatus (1991. a välja antud «Kiriku laulu- ja palveraamat», laul nr 398A). Viisi panid kirja Johannes ja Julius Muda Nissi kihelkonnas Laitse vallas elanud Madli Lembralt (67 a), kes oli pärit ning lauludki õppinud Hiiumaa Kassarilt. Tegemist oli oma aja kohta väga täpse üleskirjutusega, sest kogujad ka fonografeerisid viisi (ERA, Fon. 138a). See teisend on suure tõenäosusega praegu laiemale avalikkusele kõige paremini tuntud rahvapärane koraaliviis, mis sai arvatavasti juba 1930. aastatel kooliõpikute ${ }^{4}$ vahendusel omalaadseks vaimulike rahvaviiside olemuse ja erilisuse võrdkujuks. Laulu tuntust suurendas kindlasti ka Cyrillus Kreegi kooriseade: 1980. aastate lõpus esitasid koorid laulu nii Kreegi seades kui ka ühehäälsena, väga sageli valiti just see laul kava esimeseks palaks või nimetati nii kogu programmi. .5 Folgisõprade hulgas võitis lugu populaarsust vendade Mart ja Jaak Johansoni esituses, kõlades ka nende kassetil «Põhja vahemäng» (1993).

Kolmanda ERA-s leiduva viisiteisendi on fonografeerinud Cyrillus Kreek Noarootsi kihelkonnas Spithami külas 83-aastaselt eestirootslaselt Mats Borrmanilt 1921. aastal (ERA, Fon. 193b, üleskirjutus ERA III 4, 397 (52)). Borrman laulis rootsi keeles ning laulu sõnad olid rootsikeelsest lauluraamatust («Vak opp min själ!»), kuid üleskirjutusele oli lisatud juba ka eestikeelne koraalitekst (tõlgiks ja sõnadekirjutajaks oli C. Kreegile ta abikaasa Maria Bleesi). Noarootsi kogumiskäigul ongi C. Kreek peamiselt salvestanud vaimulikke viise, sest just seal puutub ta kokku elujõulise vana koraalilaulmistraditsiooniga. Nii kogus C. Kreek nt 82-aastaselt Mats Tagerlundilt Bergsby külas 24 vaimulikku viisi ning märkis reisipäevikus, et mees oli andnud neile lauluraamatu ning öelnud: «Näidake ise, missugust laulu tahate, ma tean kõik viisid» (ERA II 30, 363).

Ülejäänud neli üleskirjutust on pärit Vormsi saarelt. Kaks viisiteisendit, millest koopiad ka Eesti Rahvaluule Arhiivis, pani kirja Rootsi muusikateadlane Olof Anderson 1931. aastal Gertrud Alkvistilt (snd 1856) ja Sofia Laktionoffilt (RKM III 1, 237 (114) < Hullo k ja RKM III 1, $313(152)<$ Sviby). Kaks viimast viisiteisendit kogus C. Kreek 1937. aastal ning need on hoiul Teatri- ja Muusikamuuseumis C. Kreegi fondis (M 11).

Kõigis ERA-s olevates selle koraali viisiteisendites kumab läbi Punscheli koraaliraamatu (esmatrükk 1839. a) viis, mida on siiski tunduvalt edasi arendatud. Põgusalt on need võtted, mida selleks on kasutatud, välja toonud Urve Lippus eestirootsi vaimulikke viise käsitledes (vt Lippus 1988: 34-35). Võrreldes Punscheli koraaliraamatus esitatuga, on rahvasuiste teisendite meloodialiin enamate kaunistustega, pikkadele silpnootidele on lisatud eel- ja järellööke või need on asendatud duoolide ja trioolidega. Kuigi meloodia põhikuju on jäänud 
üldjoontes samaks, on seda teises fraasis lihtsustatud, asendades viisi modulatsiooni (kaldumise) kordusega. Võime tõdeda, et rahvasuistena, «vana moodi konksude ja lintidega», on viisid märgatavalt liikuvamad. U. Lippuse järgi on «selline ühehäälne vaimuliku laulu kaunistamine ilmselt ürgomane, sest muusikaajaloos puutume kokku selletaolise protsessiga alates esimestest teadetest kristliku laulu kohta kuni keskaja lõpuni, mil kaunistamine mitmehäälse struktuuri keerukustesse suubus» (samas).

Vaimulikud rahvaviisid kui köitev muusikaline materjal «leiti» Cyrillus Kreegi kooriseadete vahendusel, mis jõudsid laiema avalikkuse ette ühenduses helilooja 100. sünniaastapäeva

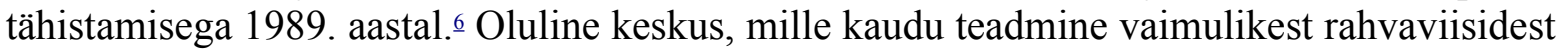
1980. aastatel levis, oli Tallinna Vanalinna Muusikamaja, kus tegutses stuudio Linnamunsikud Taivo Niitvägi juhendamisel. Linnamunsikute koostatud oli ka C. Kreegi fondi materjalil põhinev käsikirjaline noodivihik, mida kasutati õppematerjalina nii Vanalinna Muusikamajas kui ka Tallinna ja Tartu katolikes kogudustes.

Olles varem tegelenud keskaja kirikumuusikaga, lähenesid Linnamuusikud sarnaselt rahvapärastele koraaliviisidele, saates neid vanamuusika instrumentidel ning lisades põhimeloodiale burdoone ning kiht-kihilt ka teisi häli. Aja jooksul on Linnamuusikute kompositsioonid muutunud, mille kohta annavad tunnistust mitmel järjestikusel aastal tehtud samade laulude helilindistused (alates 1987. aastast). Kontsertide, väiksetiraazhiliste kassettide, uuemal ajal ka laserplaatide ${ }^{\beth}$ vahendusel on Linnamuusikute tõlgendusviis laiemalt tuntuks saanud ning on kindlasti omal moel mõjutanud ka Triskelet.

Kui Linnamuиsikuid iseloomustas algusaegadest saati vanamuusikast lähtuv tõlgendusviis, siis peagi tekkis selle kõrvale ka teistsugusest vaimsusest kantud lähenemine. Vaimulikke rahvaviise (taaskord TMM-i C. Kreegi fondi viise ümber kirjutades) hakkasid laulma folkloorirühma Leigarid lauljad Celia Roose eestvõtmisel. Leigarite esitusmaneer pürgis rahvaehtsusele. Kassetilt «Vaimulikud eesti rahvaviisid» (1991) kuuleme ühehäälset koguduselaulu, mis teadlikult püüab jätkata traditsiooni kohast, kus see 19. sajandil katkes. Kahel suvel laulis Leigarite laulurühm vaimulikke rahvalaule Vabaõhumuuseumis Sutlepa kabelis, ilmestades nii 18.-19. sajandi olustikku vahendavaid interjööre. Erinevalt Linnamuusikutest viljelesid Leigarid ka üksinda laulmist; koos lauldes polnud nende esitustes treenitud sünkroonsust, millega justkui tahtlikult jäljendati rahvaehtsat koguduselaulu. Selleski osas võib leida sarnasusi Triskele esitusega.

Celia Roose juhendamisel hakkasid vaimulikke rahvalaule laulma Leegajused, samuti paljud Viljandi Kultuurikolledzhi tudengid, kelle tõlgendusi võis kuulda ja näha 1998. aasta jõulude aegu Eesti Televisiooni erisaates. Kirikukontserdid vaimulike rahvalauludega on kuulunud lahutamatult Viljandi pärimusmuusika festivali kavadesse. Üks püsivamaid ja põnevamaid ühendusi on olnud kolmik Celia Roose, Tuule Kann ja Robert Jürjendal. Viimase aastate tegijate hulgast võib nimetada lisaks Triskelele veel Ando Kivibergi ja ta sõpru, Silvi Tumanskajat ja Sinimaniseelet..$\underline{ }$

Kindlasti on vaimulike rahvalaulude esitajaid, kes pole siinkirjutaja vaatevälja seni sattunud, veel enamgi. Igal juhul peaks seegi loend kinnitama, et huvi rahvapäraste koraaliviiside vastu on suur ning ilma vastavate trükiväljaannetetagi - levides n-ö pärimuslikke teid pidi - 
on viisid jõudnud paljude huvilisteni. Jääb vaid loota, et kunagi näevad ilmavalgust ka vaimulike rahvalaulude alased akadeemilised uurimused ning kommenteeritud allikaväljaanded. On ju arhiividesse kogutu näol tegemist väga põneva viisikogumiga mitte ainult muusiku vaid ka folkloristi jaoks ning ebaselgeid kohti nende viiside saamis- ja eluloos on veel oh-kui-palju.

\section{Viidatud kirjandus}

EKA I = Eesti kirjanduse ajalugu I. Tallinn 1965.

ERtA II = Eesti rahvaluuleteaduse ajalugu II. Tallinn 1980.

Humal, Mart 1989. Vaimulikest kaanonitest Cyrillus Kreegi hilisloomingus. Teater.

Muusika. Kino, nr 11, lk 43-46.

Järg, Tiia 1987. Rahvaviiside korjamine ja Peeter Süda. Muusikalisi lehekülgi 4. Tallinn, 1k 114-120.

Leichter, Karl 1932. Rahvaviiside korjamisest Eestis. Vanavara vallast. Opetatud Eesti Seltsi Kirjad 1. Tartu, lk 153-178.

Lepnurm, Hugo 1999. Peatükke kultusmuusika ajaloost. Tallinn.

Lippus, Urve 1988. Rahvapärane koraalide laulmine eestirootslaste külades. Teater.

Muusika. Kino, nr 12, 1k 27-39.

Masing, Uku 1964. Hans Susi 1551. a. tõlkest. Emakeele Seltsi aastaraamat 10. Tallinn, lk 121-136.

Masing, Uku; Soosaar, Albert 1956. Kolme sajandi eest värsistatud lauluraamatust. Eesti Evangeelse Luterliku Kiriku aastaraamat. Tallinn, lk 49-74. Põldmäe, Rudolf 1987.

Hernhuutlane Christoph Michael Königseer ja tema kohtuprotsess 1767. aastal. Religiooni ja ateismi ajaloost Eestis III. Tallinn, lk 172-191.

Põldmäe, Rudolf 1988. Vennastekoguduse muusikalisest tegevusest meie maal.

Teater. Muusika. Kino, nr 3, lk 67-78.

Salumäe, Jaak 1988. Ühest mõjusast ettevõtmisest, kuidas parandada kirikulaulu

haletsusväärset olukorda ka Liivimaal XIX sajandi esimesel poolel. Teater. Muusika. Kino, nr 6, lk 46-51.

Tampere, Herbert 1971. Eesti rahvaviiside süstemaatiline kogumine 20. sajandi alguses.

Emakeele Seltsi aastaraamat 17. Tallinn, lk 145-188.

Tedre, Ülo 1998. Oskar Kallas folkloristina. Oskar Kallas. Artikleid Oskar Kallase elust ja tööst. Tartu, lk 131-188.

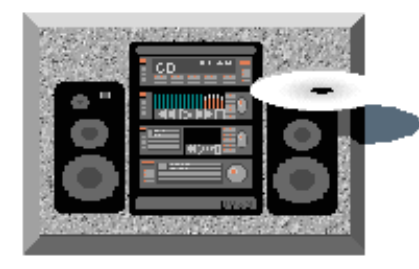

$7.6 \mathrm{Mb} . \mathrm{mp} 3$

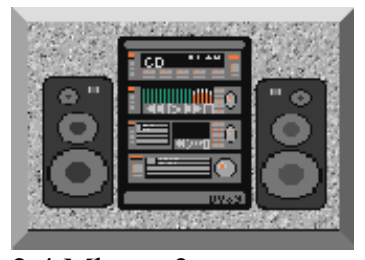

$2.4 \mathrm{Mb} . \mathrm{mp} 3$ 


\section{Kommentaarid}

1. Nt Linnamuusikud, Heinavanker, Leigarite laulurühm, vennad Johansonid, mitmed Viljandi Kultuurikolledzhi esinejad, Sinimaniseele jt.

2. «Kiriku laulu- ja palveraamat» (1991: 516) nimetab viisi autoritena Nikolas Selneckeri (1528-1592) ja Johann Crügerit (1598-1662), märkides laulu loomise ajaks aastad 1587/1649.

3. Eestirootslastelt talletati rahvapäraseid koraaliteisendeid nii enne kui pärast C. Kreegi kogumiskäike. Lähemalt vt Lippus 1988.

4. Vt nt 1937. aastal ilmunud R. Pätsi koostatud «Lemmiklaulik VI. Algkooli VI kl. ja keskkooli II-III kl. lauluvara» (lk 58-59).

5. Vt nt Eesti Kammerkoori LP «Cyrillus Kreek. Vaimulikud rahvalaulud» (1989), Eesti Projekti kammerkoori kassett «Cyrillus Kreek 1889-1962» (1990), Tallinna Kaarli kiriku okteti kassett «Mu süda, ärka üles», kammerkoor Dextera kassett (1992) jpt.

6. Vt nt helikandjaid, mis mainitud eelmises joonealuses märkuses.

7. Nt CD «Linnamuusikud AD 1994», millel kõlavad vaimulikud rahvalaulud ja M. Zielinski muusika. Samuti Püha Miikaeli Poistekoori ja Linnamuusikute CD, kus kõrvuti keskaegsed hümnid ja vaimulikud rahvalaulud.

8. Riivamisi on vaimulikud rahvalaulud kuulunud vendade Johansonide ja Rein Rannapi kavadesse. 